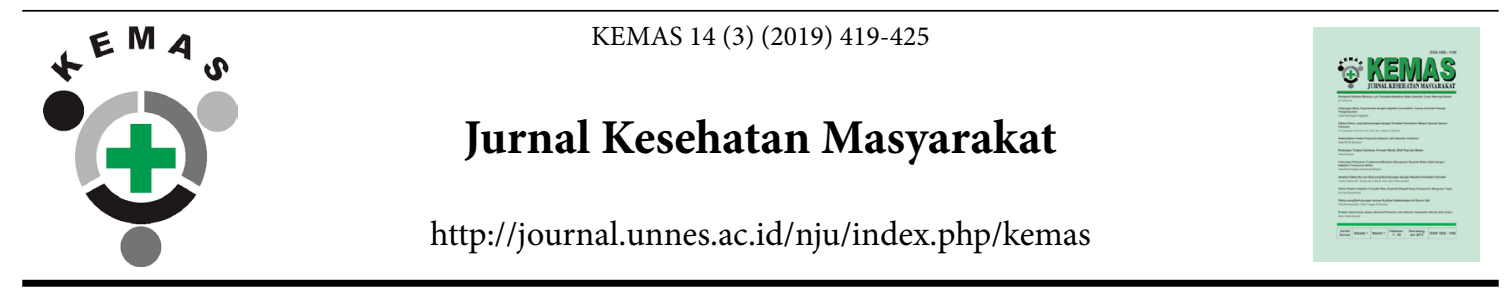

\title{
The Acceptance and the Development of Renal Function of People with Diabetes Mellitus
}

\author{
Laily Isroin ${ }^{1 凶}$ \\ ${ }^{1}$ Health Science Faculty, Universitas Muhammadiyah Ponorogo, Indonesia
}

\section{Article Info}

Article History:

Submitted November 2016

Accepted December 2017

Published March 2019

\section{Keywords:}

Chronic renal failure,

diabetes mellitus,

reception disease,

renal function

\section{DOI}

https://doi.org/10.15294/

kemas.v14i3.8089

\begin{abstract}
Chronic renal failure (CRF) is a silent killer disease. CRF disease is mainly caused by diabetes mellitus and hypertension.Patients with diabetes mellitus should be able to accept the disease so that it can control blood sugar and blood pressure. Sectional analytic study design to measure self-management that includes cognitive, self-efficacy, psychological, social and environmental patients which associated with decreased renal function, blood pressure and blood sugar. The study was conducted in dr. HarjonoHospital Ponorogo with a sample of patients with hypertension and diabetes mellitus outpatient. Total sample of 42 patients with diabetes mellitus were taken by purposive. Analysis using chi square test and the magnitude of the risk factors using OR. There was a significant correlation between the level of acceptance of the disease with glomerular filtration rate (GFR) and receiving negative disease risk 4 times the decline in GFR compared with positive reception disease. Patients with diabetes mellitus who can not control blood sugar normal it will be at risk of decreased GFR was 2.07 times compared with patients whose blood sugar normal and stable. Patients with diabetes mellitus GFR decreased by 3 to 5 degrees of $64.3 \%$.The decline in GFR at level 5 hemodialysis patients require lifelong therapy. This will reduce the productivity of patients and social and economic burden to both family and government.
\end{abstract}

\section{Introduction}

Cases of chronic renal failure are currently increasing rapidly, especially in developing countries. Chronic renal failure has become a major health problem worldwide, because it increases morbidity, mortality, adds social and economic burdens to sufferers, families and the government. Based on data released by PT. Askes in 2010 the number of patients with renal failure was 17,507 people, then increased by more than five thousand in 2011 with a fixed number of 23,261 people, then increased to 24,141 people in 2012 . It is likely that in 2014 there will be an increase in renal failure due to the population of people with diabetes and hypertension is also increasing. According to IDF (International Diabetic Faundation) data, Indonesia's position ranks 6 th in the world from a list of countries with estimates of diabetics. Cases of renal failure in Indonesia can stick out in cases of renal failure in the United States.

According to the medical record data of RSUD dr. Harjono Ponorogo the number of people with diabetes mellitus continued to increase in the last three years, namely in 2010 amounting to $31.20 \%$. The incidence of chronic renal failure also increased by $201.27 \%$. The cause of chronic renal failure in Dr. Harjono Ponorogo's General Hospital 63.4\% was caused by diabetes mellitus and $56.2 \%$ was caused by 
hypertension. The results of Isroin (2012) early detection of the Recitation Committee Sunday Morning Al Manar Muhammadiyah Ponorogo University there were $11.92 \%$ of pilgrims who had experienced a decline in third degree renal function without experiencing complaints. The congregation just realized and felt the benefits of checking renal function early and periodically, so that renal damage can be slowed, even stopped by changing an unhealthy lifestyle into a healthy lifestyle.

People with diabetes mellitus must be able to solve problems, make decisions in response to fluctuations in signs and symptoms and take action to change behavior so that it can slow renal damage. Self-management is the compliance and support partner of individuals in the treatment and care of themselves. Patients must be able to identify problems, set goals, monitor and manage symptoms (Linberg, 2010). According to Smith (2010) the success of self management requires cognitive readiness, self-efficacy, psychology, social, physical and environmental. Psychological factors are the most common barrier and are largely due to lack of motivation. Knowledge is the most important facilitator for self-efficacy, social factors also play a role in self-management. Social factors identified as determinants of health status include poverty, stress, employment, education, development \& growth of the environment in childhood, transportation, drug addiction, smoking, alcohol and diet (Hatma, 2011).

Changes in human lifestyles due to urbanization, modernization, and globalization have led to an increase in Non-Communicable Diseases (NCD) including DM. The World Health Organization (WHO) has recommended that centralizing NCD control through three main components, namely risk factor surveillance, health promotion, and prevention through innovation and health service management reform. This effort is intended to increase knowledge, public awareness, willingness to behave well, and prevent the occurrence of NCD and its complications (Umayana \& Cahyati, 2015). One of the efforts to prevent and slow down complications of renal function in DM patients is to accept the disease. People with DM must realize that they themselves are the place of acceptance and commit to take action to be faced when socializing. Acceptance and commitment have a huge impact on the development of the client's condition with anxiety will be better. Acceptance means accepting, so here it is emphasized that someone must first understand the circumstances, after which he can accept the conditions. Acceptance, awareness and use of personal values to deal with long-term internal stressors can help a person to identify his thoughts and feelings, then accept the conditions for making changes that occur, commit to himself even though in his struggle he must meet unpleasant experiences. DM patients must be committed to keep blood sugar stable so that it will slow down the process of decreasing renal function.

Prevention is the most important thing to reduce the number of patients with renal failure. This disease is dangerous, but can be prevented. One of them is by increasing awareness or knowledge of people who have chronic renal failure comorbidities about the importance of maintaining renal health. Puskesmas need to look for techniques to be able to realize the implementation of community empowerment from NCD Integrated Coaching for early detection, prevention and control of NCD (Anita et al, 2016). Self-management in preventing complications is one of the steps of disease control to realize a self-care program from WHO. According to WHO / SEARO self-care as a behavior where individuals, families, neighborhoods and communities undertake promotive, preventive, curative and rehabilitative actions to enhance their health. The self-care approach is expected to detect diseases early and costs will be cheaper. The aim of the study was to analyze the social influence and acceptance of diabetes mellitus in preventing chronic renal failure

\section{Method}

This research is descriptive and observational for mapping the self-management readiness of DM patients in preventing chronic renal failure based on knowledge readiness, self-efficacy, psychological, social, physical and environmental. This research was conducted at the internal medicine clinic at dr. Harjono Regional Hospital of Ponorogo. The sample selection in this study used purposive sampling. 
Sample size was 42 respondents. The instrument in this study used primary and secondary data sources taken from patients' medical records and questionnaires from Smith (2010) which were modified by researchers. The disease and social acceptance questionnaire used a Likert Scale questionnaire. Measurement of random blood sugar and creatinine to calculate the glomerulus filtration rate (GFR) in collaboration with the dr. Harjono Regional Hospital of Ponorogo.

Data analysis was carried out quantitatively and adjusted to the objectives to be achieved in this study, with statistical tests covering 3 types, namely univariate analysis used to analyze descriptively the characteristics of each variable with frequency distribution to be displayed in the form of narratives and tables. The description of the characteristics of the research subjects produced included age, education level, occupation and economic status. Bivariate analysis was carried out to determine the relationship of 2 variables in both groups between independent variables and dependent variables or dependent variables with disrupting variables. The statistical test used to determine whether or not there is influence between the two formal form variables is Chi Square $\left(\mathrm{X}^{2}\right)$.

\section{Result and Discussion}

The average age of DM patients is 59.42 years. Age 59 is an advanced age where degenerative processes occur which will aggravate the process of decreasing renal function in DM patients.

Table 1 Distribution of Diabetes Mellitus Respondents' Age Group on Internal Medicine Clinic dr. Harjono Regional Hospital of Ponorogo July - August $2016 \quad(\mathrm{n}=42)$

\begin{tabular}{cccccc}
\hline Variable & $\mathrm{N}$ & Min & Max & Average & SD \\
\hline Age (P) & 42 & 45 & 78 & 59.42 & 8.88
\end{tabular}

Source : Primary Data 2016

Demographic data of DM patients are $61.9 \%$ female participants, $31.1 \%$ work as farmers and private employee, and mostly are high school educated $42.9 \%$. Most often it is described as a limitation of patients in education such as a lack of understanding of what is taught to the consequences they have to experience, the inability to educate themselves and the utilization of health facilities. The average duration of illness are 6 years or $64.3 \%$, less than 10 years. The average time between diabetes to the emergence of renal failure is 20 years. Uncontrolled diabetes will accelerate renal failure. Diabetes is the most common cause of renal failure in addition to hypertension

Table 2 Frequence Distribution of Diabetes Mellitus Respondents' Characteristic on Internal Medicine Clinic dr. Harjono Regional Hospital of Ponorogo July - August 2016 ( $n=42)$

\begin{tabular}{lll}
\hline Respondents' Characteristic & Numbers & Percentage \\
\hline Sex & & \\
Male & 16 & 38.1 \\
Female & 26 & 61.9 \\
Education & & \\
Elementary & 8 & 19.0 \\
Junior High & 10 & 23.8 \\
Senior High & 18 & 42.9 \\
University & 6 & 85.7 \\
Work & & \\
Farmer & 13 & 31.0 \\
Entrepreneur & 5 & 11.9 \\
Private Employee & 13 & 31.0 \\
State Employee & 11 & 26.2 \\
\hline Source: Primary Data 2016 &
\end{tabular}

Source : Primary Data 2016 
(Buren, 2011).

Though had been suffered from DM for 6 years, random blood sugar of DM patients averagely were still more than normal, namely $225 \mathrm{mg} / \mathrm{dl}$. GFR of DM patients at normal levels (level 1 and 2) were 15 respondents (35.71\%) and abnormal GFR levels (level 3.4.5) were 27 respondents (64.29\%).

Illness acceptance has a significant relation with a decrease in GFR ( $\mathrm{p}$ value $=$ 0.043 ) and the negative illness acceptance has a risk of 4 times GFR decrease compared to positive illness acceptance.

Diabetes is the number one cause of chronic renal disease. Diabetic nephropathy (ND) is a microvascular complication, which is a complication that occurs in fine blood vessels (small). This is due to damage to the capillary arteries in the renals which cause glomerular damage. High levels of sugar in the blood will make the renal structure change, causing its' function to be disrupted. Respondents in this study had for an average of 6 years suffered from DM, but the average GDA was still more than normal. The highest level of GFR was at level III, which was $45.3 \%$. The results of this study are aligned with the results of Buren's study (2011) mentioned the rate of GFR in patients with diabetes mellitus was $8.9 \%$ level I, $12.8 \%$ level II, $19.4 \%$ level III, and $2.7 \%$ level IV and V. Although $52.38 \%$ of patients can receive the disease, they can not control the normal GDA as evidenced by the average GDA above normal, which is $225 \mathrm{mg} / \mathrm{dl}$ and $66.67 \%$ of the patients has higher than normal blood pressure. Social contact is sometimes described as a facilitator

Table 3 Frequence Distribution of Illness Duration. Diabetes Mellitus Respondents' Random Blood Sugar on Internal Medicine Clinic dr. Harjono Regional Hospital of Ponorogo July - August 2016 $(\mathrm{n}=42)$

\begin{tabular}{lll}
\hline Variable & Numbers & Percentage \\
\hline Diabetes Mellitus Illness Duration & & \\
$>10$ years & 15 & 35.7 \\
10 years & 27 & 64.3 \\
Average Random Blood Sugar & & \\
Normal & 14 & 33.33 \\
High & 28 & 66.67 \\
GFR Level & & \\
1 & 3 & 7.1 \\
2 & 12 & 28.6 \\
3 & 19 & 45.3 \\
4 & 5 & 11.9 \\
5 & 3 & 7.1 \\
\hline
\end{tabular}

Source : Primary Data 2016

Table 4 Relation between GFR and Diabetes Mellitus Patients' Illness Acceptance on Internal Medicine Clinic dr. Harjono Regional Hospital of Ponorogo July - August 2016 (n=42)

\begin{tabular}{|c|c|c|c|c|c|c|c|c|}
\hline \multirow{3}{*}{ Variable } & \multicolumn{4}{|c|}{ Illness Acceptance } & \multirow{2}{*}{\multicolumn{2}{|c|}{ Total }} & \multirow{3}{*}{ OR } & \multirow{3}{*}{ P-value } \\
\hline & \multicolumn{2}{|c|}{ Positive } & \multicolumn{2}{|c|}{ Negative } & & & & \\
\hline & $\mathrm{N}$ & $\%$ & $\mathrm{n}$ & $\%$ & $\mathrm{n}$ & $\%$ & & \\
\hline \multicolumn{9}{|l|}{ GFR } \\
\hline Normal & 11 & 73.33 & 4 & 26.67 & 15 & 100 & 4.00 & 0.043 \\
\hline Decline & 11 & 40.74 & 16 & 59.26 & 27 & 100 & & \\
\hline
\end{tabular}

Source : Primary Data 2016 
and sometimes as an obstacle to compliance with DM diet. Family and friends are most oftenly quoted with their effects depending on their willingness to learn about patients' dietary needs and support them in making necessary lifestyle changes (Smith, 2010). Acceptance is a very important stage in relation to a patient. Illness acceptance facilitates adaptation, that is, the process by which a patients adjust to their new life-situation with the disease. Illness acceptance gives patients a sense of security, increases trust in doctors and methods of treatment, patients actively participate in care, and instill an optimistic and hopeful attitude towards life (Lewko et al., 2007).

A study conducted on diabetics said that acceptance of the disease had a direct impact on adherence to the recommended treatment as well as facing obstacles during coping with the disease (Lickiewicz et al., 2010). Acceptance means accepting, so here it is emphasized that someone must first understand the situation, after which he can accept his condition. Acceptance, awareness and use of personal values to deal with long-term internal stressors that can help a person to identify his thoughts and feelings, then accept the conditions for making changes that occur, commit to himself even though in his struggle to have unpleasant experiences. People with DM must be able to control the suffering experienced, realizing that acceptance and awareness is an alternative to survival in the conditions faced, realizing that acceptance will be formed because of the presence of thoughts and what is said, realizing that yourself as a place of acceptance, committed will be faced, understanding that the purpose of a life journey is to choose values to achieve a more valuable life and commit to prevent stable sugar. Acceptance of limitations due to diabetes contributes to better motivation, achievement of goals, and thus to overcome difficulties. Patients who know and accept their disease are more motivated to overcome difficulties, and are more active in dealing with challenging situations (Bien et al., 2016).

Illness acceptance is considered a significant problem in patients with chronic diseases. Lack of acceptance can lead to lower compliance for medical care and delay in treatment. The higher the acceptance, the lower the level of negative reactions and emotions felt by the patient because of his illness and the treatment process that he lived. According to Smit (2010) social barriers to compliance include a lack of support from family, friends, providers and colleagues, special events such as eating in restaurants and holiday meetings, and continuing work. Often, DM patients report not using objective measurements in compliance diet. Psychological factors also facilitate compliance, that patients are personally responsible for themselves and are able to be independent in maintaining the right time, number and type. The low level of adherence to self-care planned by health workers has resulted in two major health problems, namely a decrease in the quality of patients' health and increased medical costs. In addition, low adherence is closely related to increased recurrence, patients will be hospitalized again, decreased functional ability, decreased quality of life and earlier death (Alspach, 2011).

The most frequently discussed facilitator of following diet recommendations is knowledge, with accurate self-assessment and positive psychological factors also described as having a beneficial role. The willingness of health workers to spend time consulting is very much needed by patients. The polyclinic in the hospital provides more time than in the puskesmas. The results of Prihandana's study (2012) show that participants besides control also consulted their doctors. A study in Pakistan where "general practitioner" spends 10 minutes on consulting patients and turns out to provide benefits in improving patient compliance Making time for consultation with patients will increase compliance in controls (Qureshi et al., 2007). The most talked about barriers are psychological, especially those associated with a lack of overall motivation to maintain a diet. Social networks such as family, friends and colleagues sometimes facilitate and sometimes inhibit achieving diet goals. Most often there is also a lack of motivational involvement to change their behavior. Research has been surprising that some patients cannot accurately interpret the information contained in food labels (Rothman et al., 2006). The willingness of family and friends to learn about dietary needs of DM patients is needed so that 
they can support DM patients in making the necessary lifestyle changes (Del, 2007).

Illness acceptance facilitates adaptation, that is, the process by which patients adjust to their new life-situation with the disease. Illness acceptance gives patients a sense of security, increases trust in doctors and methods of treatment, patients actively participate in care, and instill an optimistic and hopeful attitude towards life.

\section{Conclussion}

There is a significant relation between illness acceptance and the glomerular level of filtration rate (GFR). People with DM who have negative disease reception have a risk of 4 times a decrease in GFR compared to receiving positive disease. Patients with diabetes mellitus who cannot control normal blood sugar will risk 2.07 times a decrease in GFR compared to patients whose blood sugar is stable.

Most patients with diabetes mellitus who experience a decrease in GFR level 3 to 5. Patients with DM who are not able to control blood sugar levels within normal limits will experience a process of decreased renal function.

The Management Program for the Prevention and Control of Risk Factors for Non-Communicable Diseases should not only prioritize the physical needs of DM patients, but also be related to the psychological factors of patients in receiving the disease. The lack of acceptance of DM patient can lead to lower compliance and the higher acceptance lead to more understanding that the purpose of a life journey is to choose values in achieving a more valuable life and commit to control stabil blood sugar.

\section{Acknowledgement}

I would like to acknowledge the Indonesian Ministry of Research and Technology, Director and Head of Internal Medicine and Neurology at dr. Harjono Regional Hospital of Ponorogo. Also my highest appreciation to the respondents who were willing to participate in this research.

\section{References}

Alspach, J.A., 2011. Medication Adherence Before and After A Stay in Critical Care: What Nurses Need to knor. Critical Care Nurse, 31 (4), pp. $10-14$
Anita, B., Febriawati, H., \& Yandrizal., 2016. The Role Of Public Health Centers (Puskesmas) As The Gatekeeper Of National Health Insurance. Jurnal Kesehatan Masyarakat: KEMAS, 12(1), pp. 76-89.

Bień, A., Ewa, R., Angelika, K., \& Grażyna, I., 2016. Factors Affecting the Quality of Life and the Illness Acceptance of Pregnant Women with Diabetes. Int J Environ Res Public Health, 13(1), pp. 68.

Buren., 2011. Hypertension in Diabetic Nephropathy: Epidemiology, Mechanisms, and Management. Adv Chronic Renal Dis, 18(1), pp. 28-41.

Del Sindaco, D., Pulignano, G., \& Minardi, G., 2007. Two-year Outcome of a Prospective, Controlled Study of a Disease Management Programme for Elderly Patients with Heart Failure. J Cardiovasc Med (Hagerstown), 8(5), pp. 324-329.

Hatma., 2011. Sosial Determinan Dan Faktor Risiko Kardiovaskuler (Analisis Data Sekunder Riskesdes 2007). Buletin Jendela Data dan Informasi Kesehatan. Semester II.

Isroin., 2012. Deteksi Dini Penyakit Gagal Ginjal Kronik, Jurnal Warta Unmuh Surakarta,15 (2), pp. $140-148$.

Lewko, J., Polityńska, B., Kochanowicz, J., Zarzycki, W., Okruszko, A., Sierakowska, M., Jankowiak, B., Górska, M., Krajewska-Kułak, E., \& Kowalczuk, K., 2007. Quality of Life And Its Relationship to the Degree of Illness Acceptance in Patients with Diabetes and Peripheral Diabetic Neuropathy. Adv Med Sci.; 52(1), pp.144-146.

Lindberg., 2010. Excessive Fluid Overload Among Haemodialysis Patient: Prevalence, Individual Characteristics and Self Regulation Fluid Intake. Acta Universitatis Upsaliensis Uppsala, pp. 9-73

Lickiewicz, B., Zwolinska-Wcislo, M., Lickiewicz, J., Rozpondek, P., \& Mach, T., 2010. Significance of Personality Features in the Illness Adaptation Process in Patients with Inflammatory Bowel Disease. Przeglad Gastroenterologiczny, 3, pp. 157-163.

Prihandana, S., 2012. Studi Fenomenologi: Pengalaman Kepatuhan Perawatan Mandiri pada Pasien Hipertensi di Poliklinik RSI Siti Hajar Kota Tegal. FIK Program Magister Ilmu Keperawatan UI.

Qureshi, N.N., Hatcher, J.. Chaturvedi, N., \& Jafar, T.H., 2007. Effect of General Practitioner Education on Adherence to Antihypertensive Drugs: Cluster Randomised Controlled Trial. British Medical Journal, 335(7628), pp. 1-8. 
Rothman, R.L., Housam, R., \& Weiss, H., 2006. Patient Understanding of Food Labels: The Role of Literacy and Numeracy. Am J Prev Med, 31(5), pp. 391-398.

Smith, K., 2010. Patient Perspectives on Fluid Management in Chronic Hemodialysis. Division of Nephrology, Department of Medicine, Vanderbilt University School of
Medicine, Nashville, TN 37212, USA. Journal Ren Nutr, 20(5), pp. 334-341.

Umayana \& Cahyati, W.H., 2015. Dukungan Keluarga Dan Tokoh Masyarakat Terhadap Keaktifan Penduduk Ke Posbindu Penyakit Tidak Menular. Jurnal Kesehatan Masyarakat: KEMAS, 11(1), pp. 96-101 